OPEN ACCESS

Edited by:

Rogelio González-González, Juárez University of the State of

Durango, Mexico

Reviewed by:

Omar Tremillo Maldonado, Juárez University of the State of

Durango, Mexico

Jesus Lavalle-Carrasco, Juárez University of the State of

Durango, Mexico

${ }^{*}$ Correspondence:

Nahom Tefera

nahomtefera319@gmail.com

Specialty section:

This article was submitted to

Oral Epidemiology,

a section of the journal

Frontiers in Oral Health

Received: 12 January 2022 Accepted: 09 February 2022 Published: 04 March 2022

Citation:

Tefera N, Mulualem D, Baye K

Tessema M, Woldeyohannes M, Yehualashet $A$ and Whiting SJ (2022) Association Between Dietary Fluoride and Calcium Intake of School-Age Children With Symptoms of Dental and Skeletal Fluorosis in Halaba, Southern Ethiopia.

Front. Oral. Health 3:853719. doi: 10.3389/froh.2022.853719

\section{Association Between Dietary Fluoride and Calcium Intake of School-Age Children With Symptoms of Dental and Skeletal Fluorosis in Halaba, Southern Ethiopia}

\author{
Nahom Tefera ${ }^{1 *}$, Demmelash Mulualem ${ }^{2}$, Kaleab Baye $^{3}$, Masresha Tessema $^{4}$, \\ Meseret Woldeyohannes ${ }^{4}$, Asrat Yehualashet ${ }^{4}$ and Susan J. Whiting ${ }^{5}$
}

${ }^{1}$ Ethiopia and Food Science and Nutrition Research Directorate Ethiopian Public Health Institute, Center for Food Science and Nutrition, College of Natural and Computational Sciences Addis Ababa University, Addis Ababa, Ethiopia, ${ }^{2}$ School of Human Nutrition and Food Science, Hawassa University, Awasa, Ethiopia, ${ }^{3}$ Center for Food Science and Nutrition, College of Natural and Computational Sciences Addis Ababa University, Addis Ababa, Ethiopia, ${ }^{4}$ Food Science and Nutrition Research Directorate Ethiopian Public Health Institute, Addis Ababa, Ethiopia, ${ }^{5}$ College of Pharmacy and Nutrition, University of Saskatchewan, Saskatoon, SK, Canada

Background: In the Ethiopian Rift Valley, ways to reduce the fluoride (F) burden from drinking water have been unsuccessful. Calcium (Ca) intake may mitigate fluorosis by binding with $\mathrm{F}$ ions and preventing absorption. The purpose of this study was to examine the association between $\mathrm{Ca}$ intake and proportion of fluorosis symptoms in school-age children in an area where $F$ levels are known to be higher than WHO limit of $1.5 \mathrm{mg}$ F/L water.

Methods: A cross-sectional survey in the Halaba zone involved 135 eligible children aged 6-13 year who were recruited to have dental fluorosis assessed by a dentist and skeletal fluorosis assessed by a physiotherapist. Dietary Ca intake was determined by 24$\mathrm{h}$ recall. Food items and samples from ground wells, taps and spring water were collected for $\mathrm{F}$ concentration. Associations were measured using bivariate logistic regression, adjusted for known confounders.

Results: Water F averaged $5.09 \mathrm{mg} / \mathrm{L}$. Total F intake was high, $10.57 \mathrm{mg} /$ day, and Ca intake was low, 520 mg/day. Prevalence of dental fluorosis (from very mild to severe symptoms) was $73.1 \%$ for younger children (6-8 years) and $68.3 \%$ for older children (9-13 years). The prevalence of children having symptoms of skeletal fluorosis ranged between 55.1 and $72.4 \%$, with no apparent age difference. Dietary F intake of children was significantly positively associated with presence of dental fluorosis. Dietary Ca intake of children was significantly negatively associated with dental fluorosis. Higher than average dietary $\mathrm{F}$ intake significantly increased the odds of developing skeletal fluorosis symptoms when measured as inability to stretch and fold arms to touch back of head. Higher than average $\mathrm{Ca}$ intake was significantly associated with decreased odds of developing skeletal fluorosis measured as inability to bend body to touch the toes or floor. 
Conclusions: High dietary F, as expected, was associated with fluorosis in children. In the presence of higher Ca intake (>520 mg/day) some fluorosis symptoms were mitigated. There is a need to improve Ca intakes as all were below recommended levels, and this nutritional strategy may also reduce burden of excess $F$.

Keywords: fluoride, fluorosis, calcium, dental, skeletal, school-age children, Ethiopia

\section{BACKGROUND}

Fluoride $(\mathrm{F})$ is a micronutrient having both an Adequate Intake (AI) recommended intake and a Tolerable Upper-Intake Level (UL) from the Institute of Medicine [1]. Its role is primarily to form fluorapatite, which makes bone stronger and teeth more resistant to decay. Prolonged ingestion of $\mathrm{F}$ at levels above the UL leads to mottled then damaged teeth (dental fluorosis) and deformed bones (skeletal fluorosis). Non-skeletal conditions such as thyroid problems, growth retardation, kidney damage, can arise [2]. Children are vulnerable to dental fluorosis as baby teeth and subsequently, permanent teeth, erupt during childhood. The AI of $\mathrm{F}$ for children ages 4-8 and 9-13 years is 1 and 2 $\mathrm{mg} /$ day, respectively. The ULs for these age groups are 2.2 and $10.0 \mathrm{mg} /$ day, respectively, showing a very narrow safe range of intake [1].

The major source of ingested $\mathrm{F}$ is in drinking water [3, 4], and the WHO [5] has set limits on drinking water F concentration of $1.5 \mathrm{mg} / \mathrm{L}$. Millions of people worldwide rely on drinking water with $\mathrm{F}$ concentrations exceeding this level, including those in the Great Rift Valley that extends through eastern Africa [6]. In the Ethiopian Rift Valley, the average F content of ground water used for drinking is $6.03 \mathrm{mg} / \mathrm{L}$ and as much as $28 \%$ of the population has dental fluorosis [7]. Afar, Oromia, and SNNPR are the Ethiopian regional states which are most affected by high F level in the drinking water supply [8], and some areas are greatly affected; for example, the prevalence of dental fluorosis in rural communities of the Ziway-Shala lake basin was reported as $62 \%$ [9].

The severity of fluorosis is associated not only with $\mathrm{F}$ dose, but also with other factors such as length of exposure, altitude, and nutritional status $[10,11]$. Fluoride is efficiently absorbed from both the stomach and small intestine without regulation [12]. However, studies in Ethiopia showed that people in diverse regions exposed to similar water $\mathrm{F}$ levels had different degrees of fluorosis severity in children [13], and variations in dietary calcium $(\mathrm{Ca})$ intakes were implicated. Calcium, a cation, binds to $\mathrm{F}$, an anion, to form insoluble salts that are not absorbed. A study performed using an animal model reported that calciummagnesium salts or a plant source of these minerals effectively reduced apparent $\mathrm{F}$ absorption, indicating support for a calciuminduced reduction in fluorosis development [14].

\footnotetext{
Abbreviations: AI, Adequate Intake; AOR, Adjusted Odd Ratio; Ca, Calcium; CI, Confidence interval; EDHS, Ethiopia Demographic and Health Survey; F, Fluoride; FFQ, Food frequency questionnaire; IOM, Institute of Medicine; OR, Odds Ratio; SNNPR, Southern Nation Nationality and Peoples Region; UL, Upper Level (or upper limit); WHO, World Health Organization.
}

In Ethiopia, the extent of dental and skeletal fluorosis has been assessed in children in communities having different calcium intakes $[14,15]$; however, an association of dietary calcium intake with fluorosis using individual data has not been demonstrated. This study aimed to assess whether the prevalence of dental and skeletal fluorosis was associated with calcium intake in school-age children ages 6-13 years in Halaba, Southern Ethiopia, an area known for high $\mathrm{F}$ water levels [13].

\section{MATERIALS AND METHODS}

This study was carried out in Halaba zone, the southern part of Ethiopia. It is situated on an average altitude of $1,800 \mathrm{~m}$ above sea level with an average $750 \mathrm{~mm}$ annual rainfall which is classified as dry midland; it is located in the Ethiopian Rift Valley. The study area was selected based on a past report showing a high-water $\mathrm{F}$ content in the community ( $\sim 5 \mathrm{mg} / \mathrm{L})$ [13].

\section{Study Design}

The study design was a cross-sectional survey in the village (kebele) of Lay Arsho in the Halaba zone. In the kebele, households had been identified for a larger study [16] and those with eligible school-age children were invited to participate in this sub-study.

\section{Study Period}

Dental and skeletal fluorosis assessments were done in January 2018 during a larger survey involving two kebeles [16] during which time the same study personnel also collected data from the mothers of these school-age children, including dietary calcium using a food frequency questionnaire. The dietary intake data by 24-h recall, food, and water samples were collected in January 2019. Fluoride levels of food and water samples were analyzed in April-May 2019.

\section{Target and Study Population}

The study population was all eligible school-age (6-13 years) children living in the study area for at least 6 months prior to this study. In this age group, dental fluorosis can be identified, and prevalence rates can be compared to previous studies. Those children who reported having any illness in January 2018 were excluded from the study. The sample size was estimated using EpiInfo Version 7.0.8.3 by considering 12\% prevalence of skeletal fluorosis among school-age children in the same study area [13], 95\% level of confidence and absolute precision $(d=5 \%)$. Since the total study population was $<10,000$, a finite population correction formula was used to correct the calculated sample size. Finally, based on the above assumptions and by considering a 
$10 \%$ non-response rate, a minimum sample size of 135 schoolage children was estimated as sufficient power to determine the level of fluorosis among school-age children.

\section{Dental and Skeletal Fluorosis Assessment}

School-age children were assessed for the presence of dental fluorosis based on the Dean index [17] which classifies dental fluorosis into 6 categories: normal, questionable, very mild, mild, moderate, and severe dental fluorosis. Further details have been published elsewhere [13]. All examinations were conducted at a health post. The examination of teeth was carried out by a qualified, experienced Ethiopian dentist. Subjects were instructed to come having thoroughly brushed their teeth. Skeletal fluorosis rates among school-age children were assessed by a qualified, experienced Ethiopian physiotherapist using published clinical symptoms and physical exercises specifically for this purpose $[13,18,19]$. Individuals who could not perform the physical exercise in the endemic areas, as well as display stiffness of the back and neck muscles, unable to bend forward or to stand straight were categorized as having skeletal fluorosis [13].

\section{Determination of Fluoride From Food and Water}

During the dietary intake data collection in 2019, 20 types of food items consumed by the households were identified. From each category of identified food items, at least $0.5 \mathrm{~kg}$ of each food sample was collected from households by the composite sampling method. In the study area, the community used tap, ground, and spring water sources, therefore a one-liter water sample was collected from each of these water sources.

Food samples collected from different households were dried, ground, and homogenized using a drying oven, miller, and homogenizer, respectively, for F analysis. Samples of $0.5 \mathrm{~g}$ were weighed to the nearest $0.1 \mathrm{mg}$ directly into nickel crucibles. The samples were covered with $5.0 \mathrm{ml}$ of $8 \mathrm{M} \mathrm{NaOH}$, and carefully mixed. The crucibles were put on a hot plate for evaporation to dryness before they were covered and put into the muffle furnace for combustion. The temperature program for the muffle furnace was set at $200^{\circ} \mathrm{C}$ for $\sim 16 \mathrm{~h}$ after which the temperature was increased to $525^{\circ} \mathrm{C}$ and kept there for $3 \mathrm{~h}$. The crucibles were cooled, $15 \mathrm{ml}$ distilled water was added, and the crucibles were put on a hot plate to aid the dissolution of the fusion cake. After $\sim 2 \mathrm{~h}$, the sample solutions were transferred to $50 \mathrm{ml}$ capped plastic tubes. The sample solutions were neutralized using concentrated and then diluted $\mathrm{HCl}$. Concentrated $\mathrm{HCl}$ was added dropwise until the $\mathrm{pH}$ decreased from 12.0-13.0 to 8.0-8.5. Diluted $\mathrm{HCl}$ was added dropwise until the $\mathrm{pH}$ decreased from $8.0-8.5$ to $7.2-7.5$. The $\mathrm{pH}$ meter was calibrated by $\mathrm{pH}$ buffers 7.0 and 10.0. The sample solution was diluted to $50 \mathrm{ml}$ with distilled water and stored in $50 \mathrm{ml}$ air-tight plastic tubes until analyzed. Aliquots of $5 \mathrm{ml}$ were taken out for analysis after the ash had settled and the solutions were clear. Care was taken to avoid the settled ash. Before analyzing, $0.5 \mathrm{ml}$ TISABIII was added to obtain a $\mathrm{pH}$ of 5.2-5.4, which is the optimal $\mathrm{pH}$-range for $\mathrm{F}$ determination. Reagent blanks were always prepared together with the samples. The F levels of standard solutions and sample solutions were measured in ppm using a fluoride ion-selective electrode. For all food samples, $1 \mathrm{ml}$ of $100 \mathrm{ppm} \mathrm{F}$ standard was spiked for the verification of the accuracy of the method in terms of $\%$ recovery [20].

For community water analysis, $5 \mathrm{ml}$ of buffer solution was added followed by $5 \mathrm{ml}$ of the water sample, into a measuring cell. An equal amount of buffer solution was also added for working standards. The electrode was calibrated by working standards starting from most diluted to concentrated standard. The concentration of the solutions was directly measured in ppm by using a F ion-selective electrode. A detailed description of this method has been published [13].

\section{Dietary Intakes}

The type and amount of food consumed by the study participants were collected by a 24 -h dietary recall method using a prestructured questionnaire developed based on internationally recognized multiple-pass methods [21]. Additionally, the dietary intake data for children was collected by a pre-structured 16 item food frequency questionnaire (FFQ) that focused on foods in the region that were good sources of calcium, following Wu et al. [22] methodology for a calcium FFQ as we described recently [16] for use in Ethiopia. The Ethiopian food composition table was used to estimate the dietary calcium intake of study subjects. Total F intake was estimated by using food and water F content analyzed in this study and from values from our previous research [13].

\section{Data Analysis}

The 24-h dietary data was estimated by Nutri-survey software whereas Microsoft excel was used for FFQ data estimation. Data were entered and analyzed using SPSS version 20. Bivariate logistic regression was used to look for the association between the dependent and independent variables. All variables which show statistical associations at $p<0.25$ during bivariate analysis were a candidate for the multivariate analysis. For dietary $\mathrm{Ca}$ and $\mathrm{F}$, the intake derived from the 24 -h recall was used in regression analyses. Multivariate logistic regression analysis was done to see the association between the independent variables with the dependent variable by controlling possible cofounders. Lastly, AORs at $95 \%$ a confidence interval (CI) with a $p<0.05$ were used as statistically significant predictors and reported. Descriptive statistics, such as mean and frequency were used to display study results.

\section{Ethical Clearance}

Ethical approval was obtained from Addis Ababa University (AAU) with the reference number CNSDO/204/11/2018. The study was conducted according to rules and guidelines of the Research and Ethical Clearance committee (RECC) of Addis Ababa University which is called CNS-IRB. Woreda (district) health, kebele (subdistrict) administrators, and health extension workers have briefed the objective of the study. Households gave consent for their child's involvement in dietary data collection and dental and skeletal fluorosis assessment. The study participants (caregivers and children) were informed about the objective of the study. 
TABLE 1 | Socio-demographic characteristics of school-age children ( $n=127)$ aged 6-13 years from selected one kebeles, Halaba zone, SNNPR Ethiopia, 2019.

\begin{tabular}{lc}
\hline Variables & Frequency (\%) \\
\hline Children's age (y) & $67(52.8)$ \\
$6-8$ & $60(47.2)$ \\
$9-13$ & \\
Children's sex & $68(53.5)$ \\
Male & $59(46.5)$ \\
Female & \\
Educational status of children & $83(65.4)$ \\
In school & $44(34.6)$ \\
Not in school & \\
Household occupation & $127(100)$ \\
Farming & \\
Household Religion & $2(1.6)$ \\
Orthodox Christian & $118(92.9)$ \\
Muslim & $7(5.5)$ \\
Protestant Christian & \\
Agricultural land size & \\
$</=1 / 2$ Hectare & $36(28.3)$ \\
Sources of drinking water & $108(85)$ \\
Motor pump groundwater & $19(15)$ \\
Spring water & \\
\hline Tap water & \\
\hline Mectare & \\
\hline
\end{tabular}

\section{RESULTS}

\section{Subjects}

There were 127 children who completed this study, which is a response rate of $94 \%$ among 135 children initially recruited. Socio-demographic characteristics of the households and children enrolled in this study are shown in Table 1. The mean age (SD) of school children was 7.8 (1.9) years. About one-third $(34.6 \%)$ of school-age children had not attended formal school education. The main source of income for all households included in this study was farming. Most (92.5\%) of the households were Muslim by religion. For the majority (67.7\%) of households, motor pump groundwater was the source of drinking water.

\section{Biochemical Results}

The $\mathrm{F}$ level in drinking water from different sources averaged by taking \% usage into consideration $5.09 \mathrm{mg} / \mathrm{L}$. The content of $\mathrm{F}$ in all three community drinking water supply sources exceeded the WHO limit $(1.5 \mathrm{mg} / \mathrm{L})($ Table 2).

The F content of selected food items varied between 0.83 and $13.61 \mathrm{mg} / \mathrm{kg}$ as shown in Table 3. Food items that were prepared from maize and millet, the staple foods of the community, had the highest concentration of $F$. In contrast, vegetable sources such as cabbage and potato had low concentrations of F. For all food items, \% recovery was varied between 90.4 and $107.9 \%$, which falls in an acceptable range.
TABLE 2 | Fluoride (F) levels of water collected from different sources from Halaba SNNPR, Ethiopia, 2019.

\begin{tabular}{lccc}
\hline Water type & $\begin{array}{c}\text { F level } \\
\mathbf{m g} / \mathbf{L}\end{array}$ & $\begin{array}{c}\text { Use by } \\
\text { Households } \\
\text { (\%) }\end{array}$ & $\begin{array}{c}\text { Average over } \\
\text { community } \\
\text { (mg/L) }\end{array}$ \\
\hline $\begin{array}{l}\text { Tap water } \\
\text { Motor pump }\end{array}$ & 4.73 & 67.7 & 5.09 \\
groundwater & 6.21 & 28.3 & \\
Spring water & 3.33 & 3.9 & \\
\hline
\end{tabular}

TABLE 3 | Fluoride levels of foods and beverages collected from Halaba zone SNNPR Ethiopia, 2019.

\begin{tabular}{lcc}
\hline Sample Type & F (mg/kg) & Recovery (\%) \\
\hline Injera (unknown ingredients) & 10.61 & 100.64 \\
Unleavened bread (unknown ingredients) & 13.61 & 97.25 \\
Unleavened bread, maize & 12.51 & 102.48 \\
Injera (maize, millet (1:1)) & 8.28 & 102.54 \\
Unleavened bread, millet & 4.89 & 93.70 \\
Injera [sorghum, maize, millet (1:1:1)] & 4.95 & 95.36 \\
Bread (maize) & 10.49 & 99.02 \\
Injera (millet) & 7.84 & 105.68 \\
Boiled potato and carrot & 1.6 & 92.21 \\
Rice with carrot & 3.18 & 103.64 \\
Shiro stew without tomato & 3.87 & 103.60 \\
Boiled cabbage & 0.83 & 103.18 \\
Banana & 5.26 & 107.89 \\
Taro, Colocasia antiquorum: boiled & 4.61 & 96.19 \\
Boiled beetroot & 3.2 & 102.68 \\
Cabbage and potato stew & 2.42 & 95.92 \\
Coffee (prepared from coffee leaf) & 3.5 & 104.45 \\
\hline
\end{tabular}

\section{Dietary Diversity and Dietary Intakes}

Out of seven food groups, the mean diet diversity score was 3.13. The diet was predominantly cereal-based, consumed by all children (100\%). Legumes and nut products were consumed by $30.7 \%$ of children, whereas $9.4 \%$ of children consumed dairy products. Poultry products, meat, and fish products were not consumed at all by children during the assessment. Vitamin Arich fruits and vegetables were consumed by $84.3 \%$ of children, whereas $89.8 \%$ of children consumed other fruits and vegetables (Figure 1).

\section{Calcium Intakes}

The calcium intake of these school children averaged $520 \mathrm{mg} /$ day over both age groups when assessed by 24 -h recall, and 452 $\mathrm{mg}$ /day when assessed by the FFQ (Table 4). Data from these two dietary assessment methods were highly correlated $(r=0.728$, $P<0.001)$. The FFQ which asked only about the good sources of calcium underestimated intake by only $70 \mathrm{mg}$. Intakes of the children were well-below the RDA for each age group [23].

\section{Fluoride Intakes}

The mean total $\mathrm{F}$ intake, from food and water, was $\sim 10 \mathrm{mg}$ /day by $24-\mathrm{h}$ recall, and $9 \mathrm{mg}$ by FFQ. These intakes were well-above 


\section{Frequency $(\%)$}

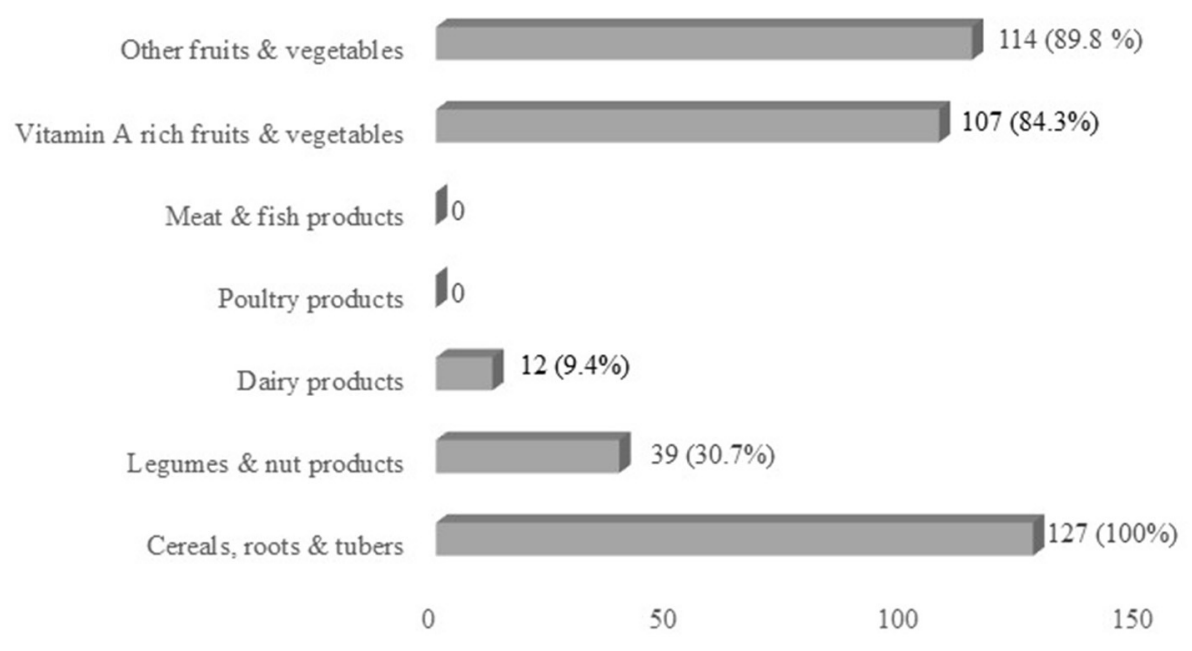

FIGURE 1 | Consumption (\%) of seven food groups by school-age children in Halaba zone, SNNPR Ethiopia.

TABLE 4 | Mean (SD) dietary calcium (Ca) and total fluoride (F) intakes of school children 6-13 years, mean (SD) in comparison with dietary standards, Halaba Zone selected kebele, SNNPR, Ethiopia (2019).

\begin{tabular}{lccc}
\hline $\begin{array}{l}\text { Intake } \\
\mathbf{m g} \text { /day }\end{array}$ & $\begin{array}{c}\text { Children } \\
\mathbf{6 - 8} \mathbf{y}\end{array}$ & $\begin{array}{c}\text { Children } \\
\mathbf{9 - 1 3} \mathbf{~}\end{array}$ & $\begin{array}{c}\text { All children } \\
\mathbf{6 - 1 3} \mathbf{~}\end{array}$ \\
\hline Ca & $N=67$ & $N=60$ & $N=127$ \\
By 24-h recall & $544(203)$ & $493(205)$ & 520 \\
By FFQ & $449(148)$ & $457(143)$ & 452 \\
RDA & 1,000 & 1,300 & \\
UL & 2,500 & 3,000 & \\
Total F & & & 10.6 \\
By 24-hour recall & $10.3(3.4)$ & $10.9(3.7)$ & 9.0 \\
By FFQ & $9.0(0.97)$ & $9.0(0.93)$ & \\
Al & 1.0 & 2.0 & \\
UL & 2.2 & 10 & \\
\hline
\end{tabular}

RDA, recommended dietary allowance; Al, Adequate Intake; UL, Upper Tolerable Intake Level. Recommended values for calcium [23] and for F [1] from the Institute of Medicine.

the UL of $\mathrm{F}$ for the younger school children and close to the UL for the older children [1]. The intakes of $\mathrm{F}$ are summarized in Table 4.

\section{Dental Fluorosis}

The overall prevalence of dental fluorosis (from very mild to severe symptoms) was $73.1 \%$ for the younger children (6-8 years) and $68.3 \%$ for the older children (9-13 years) (Figure 2), and prevalence of severe dental fluorosis was 1.5 and $10.0 \%$, respectively. This shows that in this community, more older children were experiencing dental problems due to the high $\mathrm{F}$ in water and foods, than younger children.

\section{Skeletal Fluorosis}

The prevalence of children having symptoms of skeletal fluorosis ranged between 55.1 and $72.4 \%$. More than half of the children (55.1\%) were unable to bend the body and touch the floor or toe. Around two-third (61.4\%) of the children were unable to touch their chest with their chin, and over two-third (72.4\%) of children were unable to stretch and fold arms to touch the back of the head (Figure 3). There was no apparent age difference in ability to do these exercises.

\section{Associations Between Calcium and Fluoride Intakes and Fluorosis}

As shown in Table 5, total F intake of children was significantly positively associated [AOR $(95 \% \mathrm{CI}) 3.486(1.229,9.885)]$ with the presence of dental fluorosis. Dietary Ca intake of children was significantly negatively associated [AOR $(95 \% \mathrm{CI}) 0.170(0.065$, $0.444)]$ with dental fluorosis level. Thus, while high $\mathrm{F}$ intake was related to a high prevalence of dental fluorosis, low Ca intake by children was also related to high levels of dental fluorosis. However, dietary Ca intake was not associated with total $\mathrm{F}$ intake.

Higher than average total $\mathrm{F}$ intake of children significantly increased the odds of developing skeletal fluorosis symptoms as measured as inability to stretch and fold arms to touch back of head (SF-test 2 ) both as unadjusted and adjusted OR values $(P$ $<0.05$ ); however, no significant effect were noted for the other two tests (Table 6). Higher than average Ca intake was negatively associated (at $P<0.05$ ) with each test without adjustment, but only one test showed a significant reduction in the odds of developing skeletal fluorosis which was SF test-1, i.e., unable to bend body to touch the toes or floor. Effects of age on performing SF tests was highly variable. Older children had greater odds of developing skeletal fluorosis measured as SF-test 2, even when adjusted. Sex of the child was not a factor. 


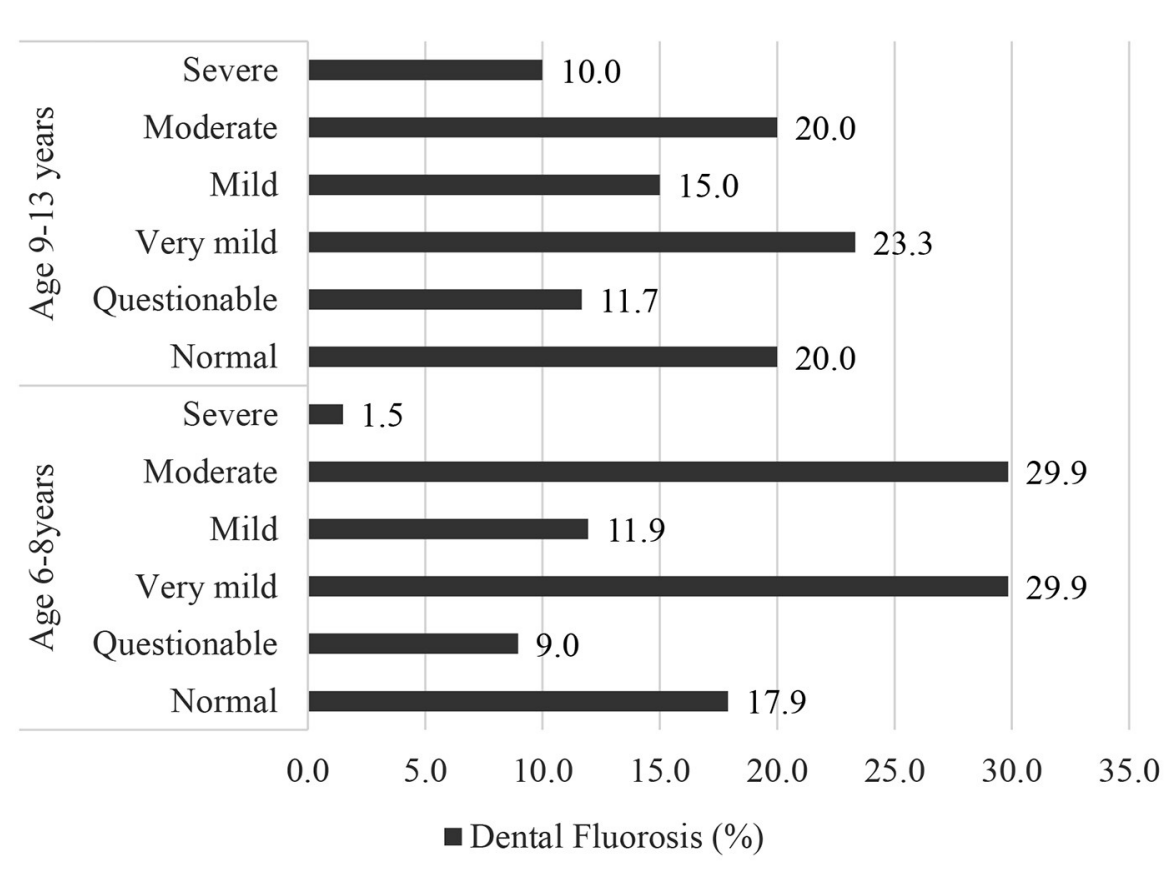

FIGURE 2 | Prevalence (\%) of dental fluorosis among school children ( N = 127) in Halaba, SNNPR Ethiopia, 2019.

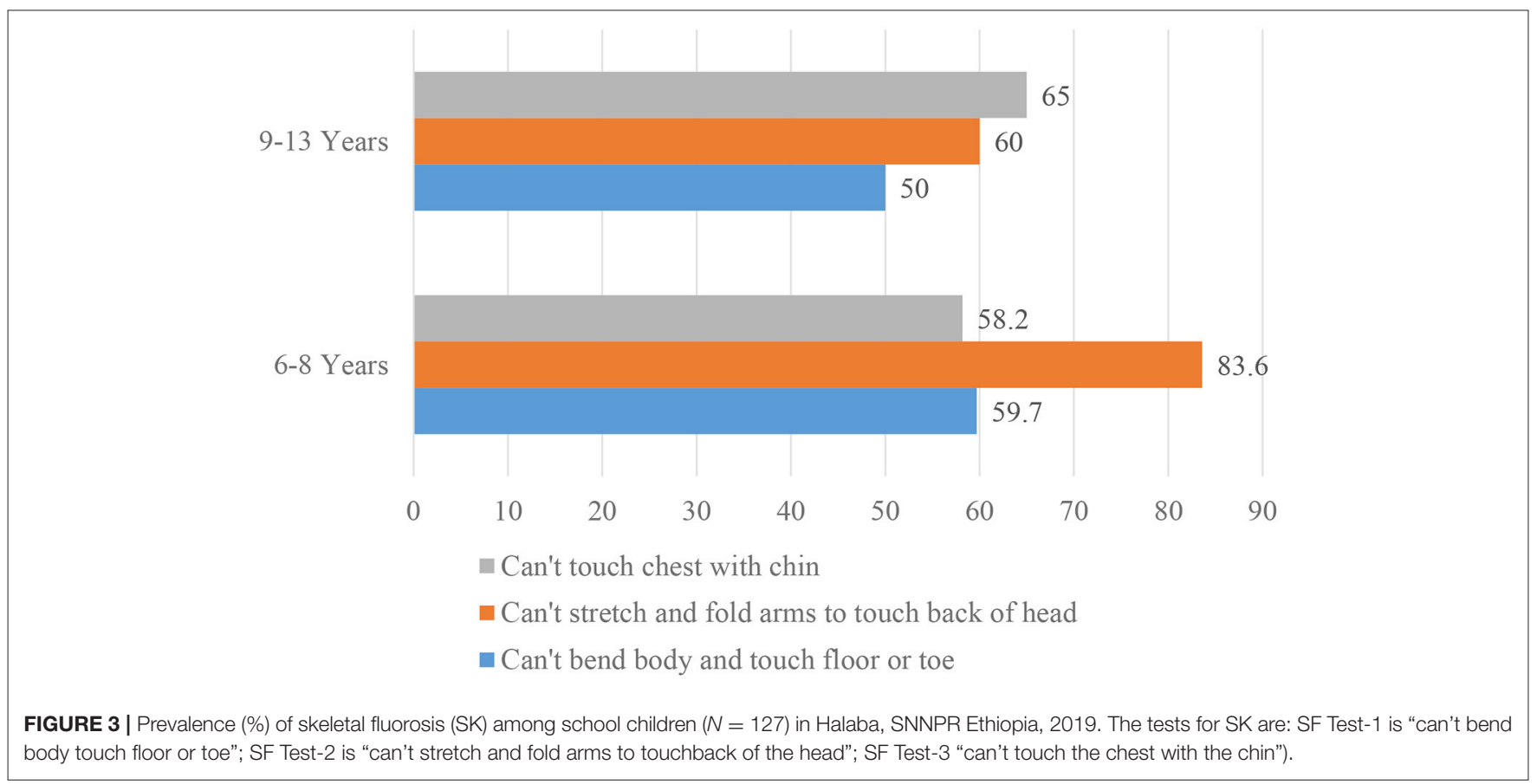

\section{DISCUSSION}

In this study, a high prevalence of dental fluorosis among school-age children was shown for this community as was the presence of skeletal fluorosis, as reported earlier [13]. For the first time we report individual dietary $\mathrm{F}$ intakes of the school children, which reached UL values, and individual dietary $\mathrm{Ca}$ intakes which were well-below the recommended intake. Our findings show that excess dietary $\mathrm{F}$ intake and low consumption of dietary $\mathrm{Ca}$ increased the odds of having dental and skeletal fluorosis in school-age children living in the Ethiopian Rift Valley. 
TABLE 5 | Predictors of dental fluorosis (DF) among school children using calcium (Ca) and fluoride (F) intakes from 24-h dietary data: logistic regression model, Halaba zone, SNNPR Ethiopia, 2019.

\begin{tabular}{|c|c|c|}
\hline \multirow[t]{2}{*}{ Variable $^{\mathrm{a}}(n=127)$} & \multicolumn{2}{|c|}{ Dental fluorosis ${ }^{b}$} \\
\hline & COR $(95 \% \mathrm{Cl})$ & AOR $(95 \% \mathrm{Cl})$ \\
\hline Dietary F (>10.57mg/day) & $5.402(2.054,14.205)^{\star \star}$ & $3.486(1.229,9.885)^{\star}$ \\
\hline Dietary Ca (>520mg/day) & $0.138(0.056,0.338)^{\star \star}$ & $0.170(0.065,0.444)^{\star \star}$ \\
\hline Age (9-13 years) & $0.793(0.368,1.706)$ & $0.510(0.203,1.283)$ \\
\hline Sex (Female) & $0.883(0.410,1.901)$ & $0.689(0.278,1.706)$ \\
\hline
\end{tabular}

${ }^{a}$ The reference groups for each variable are: Dietary $F \leq 10.57 \mathrm{mg} /$ day, Dietary $\mathrm{Ca} \leq 520$ mg/day, Age (6-8y) and Sex (male), respectively.

${ }^{b}$ The six symptoms of dental fluorosis were categorized into categorical variable (present $=1$ or absent $=0$ ) regression analysis. The first group was DF absent (normal and questionable symptoms) and the second group was any DF present (very mild, mild, moderate, and severe symptoms).

${ }^{*} P<0.05,{ }^{* *} P<0.01$.

The mean $\mathrm{F}$ intake by children was above the upper tolerableintake level of the Institute of Medicine [1] for young children age 6-8 year and close to the UL for older children. Water is the major source of excess $\mathrm{F}$ intake in that community; however, food and other beverages also had a significant contribution to excess F intake by the children. This finding supports previous studies in the Ethiopian Rift Valley $[14,23]$ and confirms that high $\mathrm{F}$ remains a problem in this area.

Dental fluorosis is a dose-response effect caused by excess $\mathrm{F}$ ingestion during the pre-eruptive development of teeth [1]. According to the results obtained in this study, the overall prevalence of dental fluorosis (very mild to severe forms) in school-age children was very high at $73 \%$, wherein $25 \%$ of children showed moderate dental fluorosis (all surfaces affected, with some brown spots and marked wear on surfaces subject to attrition) and $5.5 \%$ were affected by severe dental fluorosis (widespread brown stains and pitting). Previously it was reported that in Halaba $17 \%$ of school-age children had moderate dental fluorosis and 3\% were severe [13], and differences may reflect a trend toward increased incidence or may be the result of a difference in assessment by dentists.

Dietary F ingestion over $10.57 \mathrm{mg} /$ day, in our adjusted model, increased the odds of developing dental fluorosis by $\sim 350 \%$. After adjusting for $\mathrm{F}$ intake, a dietary $\mathrm{Ca}$ intake over $>520$ $\mathrm{mg} /$ day reduced the odds of dental fluorosis by $83 \%$ in the children. According to Cerklewski [24], Ca forms insoluble complexes with $\mathrm{F}$ which then decreases $\mathrm{F}$ absorption and its subsequent uptake into bone and teeth. It was shown over three decades ago that when $\mathrm{F}$ is ingested together with $\mathrm{Ca}$-rich foods, the bioavailability of F decreases by $40 \%$ [25]. An animal study confirmed this relationship, finding increased fecal $\mathrm{F}$ when dietary $\mathrm{Ca}$ was administered to rats subjected to a high $\mathrm{F}$ intake [13]. Dietary Ca intake of the children in our study community was well-below recommendations, a finding that adds to the growing body of research showing dietary $\mathrm{Ca}$ is a nutrient of concern in Ethiopia $[26,27]$. While milk was not a source of Ca in our research site, a study conducted in the Ziway-Shala basin of Ethiopia found that milk consumption in 1,000 people (average

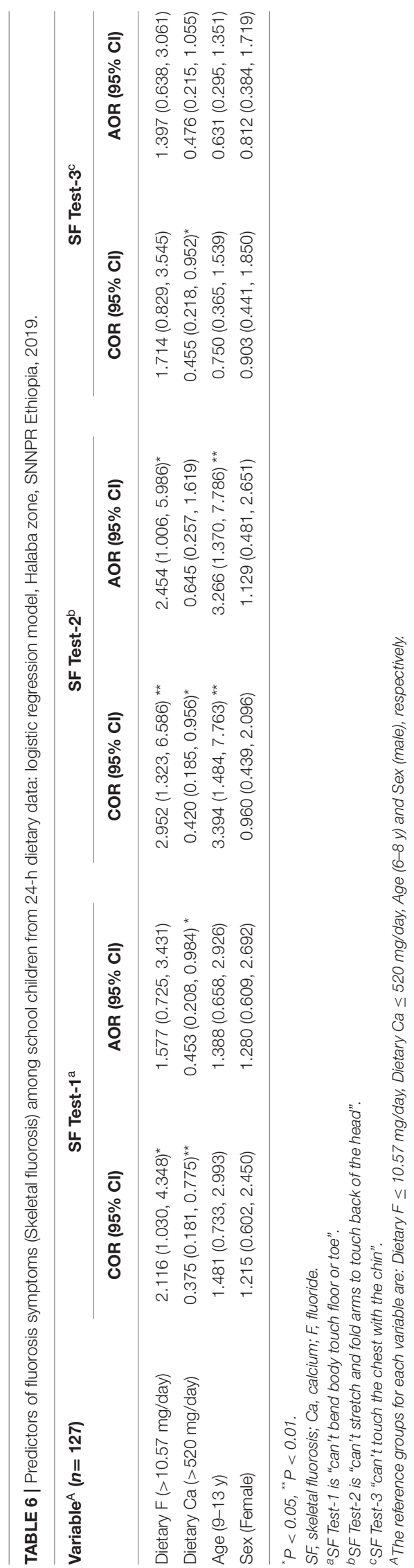


age 17 year) was inversely associated with dental fluorosis severity [9], in agreement with our findings. That study, however, did not measure skeletal fluorosis.

The results of skeletal fluorosis which was done using physical exercise tests showed that many children could not bend the body to touch the floor (SF Test-1), could not fold arms to touch the back of the head (SF Test-2), and/or or could not touch the chest with chin (SF Test-3). These results agree with an earlier study conducted in Ethiopia, which found that linear relationships between the development of skeletal fluorosis and F concentration of drinking water [28]. No report, however, has previously shown that dietary $\mathrm{Ca}$ was a factor in skeletal fluorosis. Kebede et al. [13] saw differences in prevalence of skeletal fluorosis symptoms of school-age children in Ethiopia and hypothesized that dietary $\mathrm{Ca}$ was a factor in differences between communities having similar water F levels. Our data showed a modest but significant effect of increased dietary $\mathrm{Ca}$ on improving the odds of children to be able to bend the body to touch floor or toe by $55 \%$. We also showed that high $\mathrm{F}$ intake reduced the odds of being able to stretch and fold arms to touch back of the head by close to $250 \%$. Data from young children was highly variable yet it does provide support for the findings of epidemiological research that an intake of at least $10 \mathrm{mg} /$ day for 10 or more years is needed to produce clinical signs of the milder forms of skeletal fluorosis [1].

Our study has several limitations. First, the cross-sectional nature does not allow inferences to be made on causality and rather can only indicate associations of dietary intake with chronic effects (fluorosis). Further, while dental fluorosis can be detected by qualified dental professional, the symptoms for skeletal fluorosis assessment that we used were indirect indicators, and radiographs are required to diagnose this condition. Further, we did not measure the intra-examiner reliability. Dietary data by 24 -h recall and collection of some food and water samples were done 1 year later than assessment of fluorosis signs and symptoms due to scheduling difficulties. Furthermore, some food composition data for $\mathrm{F}$ in foods that were not directly measured were taken from an American database which may vary from the Ethiopian diet.

\section{CONCLUSIONS}

The presence of dental and skeletal fluorosis in school-age children indicated a major health concern in the community, one that starts in childhood and continues throughout life. The dietary $\mathrm{F}$ intake was at or above the upper tolerable intake

\section{REFERENCES}

1. Institute of Medicine. Dietary Reference Intakes for Calcium, Phosphorus, Magnesium, Vitamin D, and Fluoride. Washington: National Academic Press (1997).

2. Panda L, Kar BB, Patra BB. Fluoride and its health impacts-a critical review. IOSR J Electron Commun Eng. (2015) 10:79-91. doi: 10.9790/2834-10417991

3. Levy S M, Warren JJ, Broffitt B. Patterns of fluoride intake from 36 to 72 months of age. $J$ Public Health level of $0.1 \mathrm{mg} / \mathrm{kg} /$ body weight recommended by the Institute of Medicine [1]. Water was the major source of $\mathrm{F}$, followed by food and beverage sources. The water F level (averaging $5.1 \mathrm{mg} / \mathrm{L}$ ) consumed by the community exceeded the WHO limit (1.5 $\mathrm{mg} / \mathrm{L}$ ) for drinking water. The dietary Ca intake of children was well-below the recommended intake levels. A simple FFQ may be used to estimate intakes of both F and Ca. Our data support the hypothesis that in the presence of excess $\mathrm{F}$ intake, a higher-thanaverage consumption of dietary Ca may mitigate the severity of dental fluorosis and skeletal fluorosis symptoms in children. This does not mean that water de-fluoridation efforts should be abandoned, but efforts for the latter have not always been successful 29). Hence, an educational intervention to improve $\mathrm{Ca}$ status such as promoting greater consumption of Ca-rich foods such as Ethiopian kale, millet, and Enset is warranted in areas experiencing fluorosis where $\mathrm{Ca}$ intakes are low.

\section{DATA AVAILABILITY STATEMENT}

The raw data supporting the conclusions of this article will be made available by the authors, without undue reservation.

\section{ETHICS STATEMENT}

The studies involving human participants were reviewed and approved by Addis Ababa University Ethical Approval Committee. Written informed consent to participate in this study was provided by the participants' legal guardian/next of kin.

\section{AUTHOR CONTRIBUTIONS}

NT, DM, KB, MT, and SW participated in the conception study design. NT, DM, MW, and AY participated in data collection. Analysis of data was by NT. The first draft of the work was by NT. All authors revised the manuscript critically for important intellectual content and reviewed the manuscript and approved the final version to be published.

\section{FUNDING}

The financial support was covered by Addis Ababa University, Ethiopian Public Health Institute, and Hawassa University.

\section{ACKNOWLEDGMENTS}

We would like to thank Dr. Aweke Kebede for his advice. 
6. Amini M, Mueller KIM, Abbaspour KC, Rosenberg T, Afyuni M, Møller $\mathrm{KN}$, et al. Statistical modeling of global geogenic fluoride contamination in groundwaters. Environ Sci Technol. (2008) 42:3662-8. doi: 10.1021/es071958y

7. Demelash H, Beyene A, Abebe Z, Melese A. Fluoride concentration in ground water and prevalence of dental fluorosis in Ethiopian Rift Valley: systematic review and meta-analysis. BMC Public Health. (2019) 19:1298. doi: 10.1186/s12889-019-7646-8

8. Tekle-Haimanot R, Melaku Z, Kloos H, Reimann C, Fantaye W, Zerihun $\mathrm{L}$, Bjorvatn $\mathrm{K}$. The geographic distribution of fluoride in surface and groundwater in Ethiopia with an emphasis on the Rift Valley. Sci Total Environ. (2006) 367:182-90. doi: 10.1016/j.scitotenv.2005.11.003

9. Kravchenko J, Rango T, Akushevich I, Atlaw B, McCornick PG, Merola RB, et al. The effect of non-fluoride factors on risk of dental fluorosis:Evidence from rural populations of the Main Ethiopian Rift. Sci Total Environ. (2014) 488:595-606. doi: 10.1016/j.scitotenv.2013.12.087

10. Akosu TJ, Zoakah AI. Risk factors associated with dental fluorosis in Central Plateau State, Nigeria. Comm Dent Oral Epidemiol. (2008) 36:1448. doi: 10.1111/j.1600-0528.2007.00387.x

11. Alvarez JA, Rezende KMPC, Marocho SMS, Alves FBT, Celiberti P, Ciamponi AL. Dental fluorosis: exposure, prevention, and management. Med Oral Patol Oral Cir Bucal. (2009) 14:E103-7.

12. Zuo H, Chen L, Kong M, Qiu L, Lü P, Wu P. Toxic effects of fluoride on organisms. Life Sci. (2018) 198:18-24. doi: 10.1016/j.lfs.2018.02.001

13. Kebede A, Retta N, Abuye C, Whiting SJ, Kassaw M, Zeru T, et al. Dietary fluoride intake and associated skeletal and dental fluorosis in school-age children in rural Ethiopian Rift Valley. Int J Environ Res Publ Health. (2016) 13:756. doi: 10.3390/ijerph13080756

14. Kebede A, Retta N, Abuye C, Whiting SJ, Kassaw M, Zeru T, et al. Minimizing bioavailability of fluoride through addition of calcium-magnesium citrate or a calcium and magnesium-containing vegetable to the diets of growing rats. Int J Biochem Res Rev. (2016) 10:23693. doi: 10.9734/IJBCRR/2016/23693

15. Malde MK, Scheidegger R, Julshamn K, Bader HP. Substance flow analysis: a case study of fluoride exposure through food and beverages in young children living in Ethiopia. Environ Health Perspect. (2011) 119:57984. doi: 10.1289/ehp.1002365

16. Mulualem D, Hailu D, Tessema M, Whiting SJ. Efficacy of calciumcontaining eggshell powder supplementation on urinary fluoride and fluorosis symptoms of women in Ethiopian Rift Valley. Nutrients. (2021) 13:1052. doi: $10.3390 /$ nu13041052

17. Dean HT. Classification of mottled enamel diagnosis. J Am Dent Assoc. (1934) 21:1421-6. doi: 10.14219/jada.archive.1934.0220

18. Shashi A, Kumar M, Bhardwaj M. Incidence of skeletal deformities in endemic fluorosis. Trop Doct. (2008) 38:231-3. doi: 10.1258/td.2008.070379

19. Susheela AK, Bhatnagar M. Reversal of fluoride induced cell injury through elimination of fluoride and consumption of diet rich in essential nutrients and antioxidants. Mol Cell Biochem. (2002) 234-235:33540. doi: 10.1023/A:1015986410685

20. Patnaik P. Handbook of Environmental Analysis. CRC Press. Boca Raton USA (1997).
21. Gibson RS, Ferguson EL. An Interactive 24-Hour Recall for Assessing the Adequacy of Iron and Zinc Intakes in Developing Countries. HarvestPlus Technical Monograph 8. Washington, DC and Cali: International Food Policy Research Institute (IFPRI) and International Center for Tropical Agriculture (CIAT) (2008). Available online at: www.harvestplus.org (accessed October 26, 2018).

22. Wu H, Gozdzik A, Lynn J, Wagner D, Cole DE, Vieth $\mathrm{R}$, et al. The development and evaluation of a food frequency questionnaire used in assessing vitamin D intake in a sample of healthy young Canadian adults of diverse ancestry. Nutr Res. (2009) 29:255-61. doi: 10.1016/j.nutres.2009.03.006

23. Institute of Medicine. Dietary Reference Intakes For Calcium and Vitamin D. The National Academic Press Washington, DC. (2011). Available online at: www.nap.edu (accessed October 26, 2018).

24. Cerklewski FL. Fluoride bioavailability - Nutritional and clinical aspects. Nutr Res. (1997) 17:907-29. doi: 10.1016/S0271-5317(97)00057-2

25. Murray JJ. Appropriate Use of Fluorides for Human Health. Geneva: World Health Organization (1986).

26. Tesfaye B, Sinclair K, Wuehler SE, Moges $T$, De-Regil LM, Dickin KL. Applying international guidelines for calcium supplementation to prevent pre-eclampsia:simulation of recommended dosages suggests risk of excess intake in Ethiopia. Public Health Nutr. (2019) 22:531-41. doi: 10.1017/S13689800180 02562

27. Tezera F, Whiting SJ, Gebremedhin S. Dietary calcium intake and sunlight exposure among children aged 6-23 months in Dale woreda, southern Ethiopia. Afr $J$ Food Agric Nutr Dev. (2017)17:12451-64. doi: 10.18697/ajfand.79.16510

28. Haimanot RT, Fekadu A, Bushra B. Endemic fluorosis in the Ethiopian Rift Valley. Trop Geogr Med. (1987) 39:209-17.

Conflict of Interest: The authors declare that the research was conducted in the absence of any commercial or financial relationships that could be construed as a potential conflict of interest.

Publisher's Note: All claims expressed in this article are solely those of the authors and do not necessarily represent those of their affiliated organizations, or those of the publisher, the editors and the reviewers. Any product that may be evaluated in this article, or claim that may be made by its manufacturer, is not guaranteed or endorsed by the publisher.

Copyright (c) 2022 Tefera, Mulualem, Baye, Tessema, Woldeyohannes, Yehualashet and Whiting. This is an open-access article distributed under the terms of the Creative Commons Attribution License (CC BY). The use, distribution or reproduction in other forums is permitted, provided the original author(s) and the copyright owner(s) are credited and that the original publication in this journal is cited, in accordance with accepted academic practice. No use, distribution or reproduction is permitted which does not comply with these terms. 